\title{
Slurs Subordinate by Cueing the Ideology
}

\section{Introduction}

In recent years, a growing number of authors (e.g. Rae Langton, Mary K. McGowan, and Ishani Maitra) have tried to understand racist hate speech in terms of Austin's speech act theory. The goal is to understand what is reprehensible about hate speech by looking at the act a speaker performs in these cases. At the center of attention in these discussions we find slurs, either directly applied to the addressee or used to talk about others. Maitra, for example, discusses the case of a man addressing an Arab woman on the subway by saying: "F***in' terrorist, go home! We don't need your kind here."1 Popa-Wyatt and Wyatt discuss a case taken from a movie where a black man, who is suspected for murder, is asked by a policeman: "Got a name boy?" 2 McGowan discusses a case of two men talking about a woman who is not present, using the term "bitch". Slur-uses of these kinds will also be the topic of this paper. In what follows, I will also use the term "hate speech" to refer to these uses.

The authors just mentioned agree that slurs subordinate the members of the targeted social group and, moreover, that there are two senses in which they do so: racist/ sexist slurs, as Maitra puts it, both cause and constitute subordination. They cause subordination insofar as they have downstream causal consequences, such as psychological distress for members of the targeted group and enhanced racist beliefs in others, making them more likely to act in ways that harm members of the targeted group. ${ }^{4}$ It is often pointed out, moreover, that slurring maintains sexist/racist practices by reinforcing racist/sexist attitudes in others. This is another way in which slurs cause subordination. However, it seems that these and possibly other kinds of consequences are not all there is to the story. It seems that, even abstracting from these effects, slurs do subordinate in other ways. It is, as it were, the act of slurring itself (even with its consequences detached), that can also be said to subordinate. In this sense, slurring can also be said to constitute subordination.

1 Maitra 2012, 100.

2 Popa-Wyatt - Wyatt 2018, 2890.

3 McGowan 2009, 399.

4 Maitra 2012, 96-97. 
In my view, the distinction between causing and constituting subordination can be elucidated by Austin's distinction between an illocutionary and a perlocutionary act. ${ }^{5}$ Austin introduces this distinction by means of examples, such as: the speaker advises the addressee to do something and thereby gets him to do it. The gist of these examples is that the perlocutionary act or effect is something the speaker does or brings about by saying something, whereas the illocutionary act is what she does in saying something. So, there is a relation of level generation between the two acts, to use Alvin Goldman's terminology. ${ }^{6}$ The speaker performs an illocutionary act, such as asking, promising, warning, and thereby (at least usually) performs a perlocutionary act or brings about a perlocutionary effect. Using this distinction, we can say that slurs cause subordination insofar as they bring about perlocutionary effects that are subordinating, and that slurs constitute subordination insofar as the illocutionary act already has subordinating characteristics.

Since it is relatively clear what the perlocutionary effects of slurs are and in what sense they are subordinating, it is relatively clear what it means to say that they cause subordination. It is less clear, on the other hand, (1.) what kind of illocutionary act is performed when a speaker slurs, (2.) how this act can be characterized more substantively than by applying to it one of the illocutionary act terms Austin or others list, and (3.) in what sense this act is one of subordination. It is the overall aim of this paper to clarify these matters.

It is important to clarify these matters, not just out of theoretical curiosity, but also because we want to know what it is that speakers do when they perform speech acts, such as those in the above examples. There is, as I said, the suspicion that slurs can not only be said to subordinate in virtue of their causal consequences, but also in virtue of the kind of act they are in themselves. And of course it is important to understand this in order to understand the persistence of sexism and racism in our society.

In order to gain a more complete understanding of slurs, we have to understand what the act itself amounts to.

\section{Background}

I will start by reviewing and criticizing some prominent proposals that have been made before presenting my own account, which builds on and refines Rebecca Kukla's. The

5 McGowan 2009, 389-390; Langton 1993.

6 Goldman 1970, 20. It is not necessary here to discuss the individuation of actions. It does not matter here whether the speaker performs two different speech acts or one speech act under two different descriptions. 
proposals I will review share a common feature, insofar as they all take it that speech acts (at least some types) constitutively involve bringing about normative consequences. That is to say, speech acts modify or create commitments and/or entitlements to act in certain ways for the addressee, the speaker, and/or others. The proposals reviewed here employ different terminologies, but the commonalities are nonetheless clearly recognizable. McGowan proposes a general conceptual framework that can be used to capture them.

McGowans framework applies to rule-governed activities in general, not only conversations, but also "dancing, playing music, walking, chess, checkers, and baseball"? "The 'rules' in question need not be explicit, formal, exceptionless or even consciously recognized. If at least some behaviours (as contributions to the activity in question) would count as out of bounds or otherwise inappropriate (as contributions to the activity in question) then that activity is rule-governed in the relevant sense." ${ }^{8}$ According to McGowan, rules are permissibility facts: that a rule is in place simply means that certain moves are permissible and others are not, i.e. they "would count as out of bounds or otherwise inappropriate".

In rule-governed activities, what is permissible (or obligatory) depends on the rules, but in many cases, it also depends on what moves have been made earlier in the activity. According to McGowan "any contribution to any rule-governed activity changes what is subsequently permissible in that activity". ' Moves in the activity have normative consequences, or as I prefer to put it: a move changes what subsequent moves participants are committed or entitled to. Thus, "when speech constitutes a move in a rulegoverned activity, it has exercitive force in virtue of enacting new permissibility facts for the activity in which it is a move. When a poker player says, 'I call', she thereby makes it impermissible for anyone else to raise the bet." ${ }^{10}$

The commonality between the approaches I will review (and the one I will defend) is that slurs are moves in a conversation and that they make changes to what is from then on permissible and obligatory in the conversation. Slurs have normative consequences, as I will say, and these normative consequences are such as to subordinate. The different proposals disagree, however, about which normative consequences slurs involve. Due to limitations of space, I will restrict myself to proposals by Rae Langton, Ishani Maitra, Popa-Wyatt and Wyatt, and Mary K. McGowan.

7 McGowan 2009, 395.

8 McGowan 2009, 395.

9 McGowan 2009, 395.

10 McGowan 2009, 396. 


\subsection{Langton: Speech Acts of a Legislator}

One way of explaining the sense in which hate speech constitutes subordination has been proposed by Langton. Langton discusses pornography, rather than slurs, but the cases seem to be largely analogous. She conceives of the production and distribution of pornographic material as a speech act, in Austin's sense, i.e., an illocutionary act by means of which the speaker also performs a perlocutionary act. To explain what kind of illocutionary act pornography is and in what sense this act can be said to be one of subordination, she compares it to the law-giving speech acts of a South-African legislator from the Apartheid-era, who can enact laws simply by performing a speech act. This legislator can, e.g. subordinate black citizens by enacting a law that deprives them of their right to vote. This is an exercitive illocutionary act. ${ }^{11}$

Applied to the case of hate speech, the proposal would be that hate speech subordinates in the sense that it deprives the members of a social group of rights and liberties. In many cases, these would be implicit social rights, liberties and duties.

Langton's account of the sense in which the speech act itself (whether pornography-propagating or racist) subordinates raises what Maitra calls the Authority Problem: ${ }^{12}$ a speaker has to occupy a special social position in order to perform a speech act that subordinates others in this way - she or he has to be the legislator. Most instances of hate speech, on the other hand, are performed by speakers who do not occupy a special social position.

\subsection{Maitra: Authority by Licensing}

Maitra's account of hate speech is designed to overcome this problem. She agrees with Langton about the sense in which hate speech constitutes subordination: the speaker deprives the members of a certain group of some of their rights and powers. Unlike Langton, however, she holds that a speaker can be authorized to do so without occupying a special social position. Rather, the speaker can be authorized in virtue of being licensed by the other participants of the conversation. ${ }^{13}$

Maitra introduces the notion of licensing in her "Traffic marshal" example: Because of an accident, it is necessary to direct drivers, so as to avoid a traffic jam and to make

11 In the context of this debate, exercitives are understood as "illocutions that confer powers and rights on people, or deprive people of powers and rights." Examples are "[a]ctions of ordering, permitting, prohibiting, authorizing, enacting law, and dismissing an employee" (Langton 1993, 304). Langton notes that this is a proper subset of what Austin 1962, 155 calls exercitives.

12 Maitra 2012, 99-102.

13 Maitra 2012, 96; 106-108; 111-117. 
room for the ambulance. One driver gets out of his car and starts directing the others. The driver is not in a social position to give these directions, and consequently the other drivers can refuse to follow them. However, as a matter of fact, they follow the direction, and by doing so, they license the first driver's authority to give directions. ${ }^{14}$

In the same way, Maitra claims, the following case of racial hate speech can be analyzed: on a subway in New York, a white male speaker addresses an Arab woman with a racial slur, in the presence of other passengers. The speaker's authority can in this setting be licensed by the fact that the other passengers do not protest. Given their "silent approval", the slur deprives the addressee of certain rights and liberties. ${ }^{15}$ I want to note here that the silent approval by which others are complicit in the subordination involves more than the fact that bystanders are somehow reluctant to speak up, even if they really disagree. That would not be sufficient to license the speaker's authority.

The following consideration indicates that a crucial element is insufficiently theorized in Maitra's account: let us start with the observation that hate speech also subordinates when no by-standers are present to license the speaker. ${ }^{16}$ To explain this, Maitra has to resort to imaginary by-standers. But then, the question is why the speaker and the addressee imagine them as not objecting. Could they not just as well imagine that they object? Maitra could respond that this would not be very realistic because we live in a racist society. ${ }^{17}$ This, however, indicates that hate speech only works against a background of a racist ideology.

The ideology is also relevant in cases in which by-standers are present. In these cases, a hate speaker is not taking a chance on whether or not they will object (as Maitra’s "Traffic marshal" does). Because of the racist ideology, he can more or less count on them to license his authority. What the hate speaker says "merely" expresses what is widely accepted in a racist society.

\subsection{Popa-Wyatt and Wyatt: Salience of Discourse Roles}

Popa-Wyatt and Wyatt propose a different solution of Maitra’s Authority Problem. On their account, slurs are exercitive speech-acts with normative consequences that subor-

14 Maitra 2012, 106.

15 Maitra 2012, 114. Maitra notes that the others are complicit in the act of subordinating the addressee. So, on second sight, it is not the act of hate speech alone that subordinates, but rather the speech act together with the silence of the others.

16 For a similar objection, see Popa-Wyatt - Wyatt 2018, 2893-2894.

17 An anonymous reviewer has suggested that bystanders may remain silent, even though they are not themselves racists, because this is "less costly". But as I just explained, this would not be enough for Maitra, because this would not license the speaker's authority to deprive the addressee of rights and powers. 
dinate others, where the normative consequences are such that no special authority is required to bring them about. They adopt McGowan's thesis that there are conversational exercitives, i.e., speech acts that alter which moves are appropriate in a conversation and how it is correct to understand certain utterances or expressions. For example, a speech act can make a certain object or a fact salient, which has consequences for how demonstratives are correctly interpreted. ${ }^{18}$

Popa-Wyatt and Wyatt adapt this idea, so as to make clear how slurs can subordinate. For this adaptation, it is first of all important that each agent/speaker has several social roles or identities; in their example, one person is an African American, a police officer, and a murder suspect. Only some of these roles are actively played at any time. Moreover, some of these social roles also figure as discourse roles and determine how it is appropriate to discursively interact with their bearers. ${ }^{19}$

Against this background, Popa-Wyatt and Wyatt show that slurs are conversational exercitives that establish permissibility facts in a discourse. A slur can change the conversational dynamics by making a social role of one of the participants salient. Because of its salience, the social role becomes the new discourse role. ${ }^{20}$ This role can suppress as much as the social role it is grounded in did, e.g. by making it appropriate in the discourse to mistrust or ignore a speaker.

Following McGowan, Popa-Wyatt and Wyatt argue that "conversational exercitives do not require authority in the way that standard exercitives do". ${ }^{21}$ There seem to be two elements in Popa-Wyatt and Wyatt's account that are meant to ensure this: first, the exercitive merely concerns a conversation and, second, it merely makes salient a role the addressee already has. Popa-Wyatt and Wyatt stress the first element, but I think the second is much more important.

First of all, the fact that an exercitive concerns a conversation is not sufficient to show that no authority is required. Opening a meeting mainly concerns discourse permissiblities, but still, performing this act requires authority. The main reason why no authority is required seems to be rather that conversational exercitives work by making something salient that is anyway part of the common ground of the conversation, viz. that certain participants have certain social roles. No authority seems to be required to bring this about.

Generally, I think it is a very promising approach to focus on the way in which slurs make social roles salient that addressees have anyway. My own view is that slurs cue the ideology, which has important similarities with this approach. However, I am not sure if the way slurs operate is best described as "making salient". More importantly, there

18 McGowan 2004, 100.

19 Popa-Wyatt - Wyatt 2018, 2888-2889.

20 Popa-Wyatt - Wyatt 2018, 2890-2891.

21 Popa-Wyatt - Wyatt 2018, 2894. 
is, as far as I can see, no reason to restrict the effect of the new salience to discourse permissibilities. If a slur makes the fact that a speaker has a subordinated social role salient, this can just as well enact permissibility facts concerning acts other than speech acts - or so I will argue in the remainder of this paper.

\subsection{McGowan: Covert Exercitives}

We have already encountered McGowan's thesis that speech acts sometimes enact conversational permissibilities. ${ }^{22}$ In a later article, McGowan argues that they can also enact permissibilities going beyond the conversational realm. In support of this claim, she first offers a rather abstract argument: ${ }^{23}$ oppression is a rule-governed activity. Since slurs contribute to oppression, they are verbal moves within this activity. Verbal moves in rule-governed activities are covert exercitives, i.e. they covertly enact permissibility facts. According to McGowan, this argument shows that speech acts enact permissibility facts of some kind, but not that they enact oppressive ones. In order to show that slurs enact oppressive permissibility facts, McGowan interprets a real world example using the terms that her abstract argument is couched within: ${ }^{24}$ a man talks to his male colleague about a woman using a degrading term. This speech act, McGowan claims, makes it acceptable to "degrade women", not just verbally, but also practically, outside conversations. It "makes women second-class citizens".

This conclusion seems wrong to me because, in McGowan's example, it is not the speech act that enacts the oppressive permissibility facts. Women are antecedently oppressed, so the oppressive permissibility facts obtain independently of the speech act. Whatever the speech act does, it does not enact these permissibility facts in the sense of bringing them about.

McGowan concedes that women are antecedently oppressed, but argues that this does not undermine her claim that slurs enact oppressive permissibility facts. That is something I would concede, but that does not answer the objection. The following is not the case: if women had not been antecedently oppressed, then the slur would have made it the case that they are oppressed. Of course a slur can contribute to maintaining the oppressing practice, but the contribution of a single slur will be rather small and, in any case, a single slur cannot institute this practice.

22 McGowan 2004.

23 McGowan 2009, 397-398.

24 McGowan 2009, 400-401. 


\section{Slurs Subordinate by Cueing the Ideology}

I have discussed and criticized different ways of explaining the sense in which hate speech constitutes subordination. It is the main goal of this paper to propose a satisfactory understanding of this phenomenon, one that meets the following requirements: (1.) Subordination in the sense to be explained should not be a downstream causal consequence of slurs. In this regard, I will take the same basic approach as the accounts just discussed: I will try to identify certain normative consequences of slurs and argue that bringing them about constitutes an act of subordination. (2.) No special authority should be required to effect this kind of subordination. (3.) The account should adequately reflect the role played by the ideology. We live in a racist society and it is only against this background that acts of hate speech can have a subordinating effect.

My proposal of how subordination is to be understood builds on Rebecca Kukla's analysis found in "Slurs, Interpellation, and Ideology". Kukla argues that slurs, at least if they are used second-personally, ${ }^{25}$ should be conceived of as interpellations with a certain content. An interpellation is a type of speech act in which a speaker calls out to an addressee as a member of a certain category. Paradigmatic examples would be "Hey you", "Hi, Eli", "Officer, could you help us, please". Interpellations have semantic content, insofar as a proper name or a social role concept is employed. ${ }^{26}$ Slurs are of the same speech act type as the above examples, the difference being that their content is derogatory and subordinating. I agree with most of what Kukla says in her article, but there are also points where I will deviate. As I will explain in due course, I would specify the normative output of interpellations somewhat differently, so as to better bring out the way they interact with the ideology. Secondly, there is a minor disagreement about the question of authority. Finally, I am dissatisfied with what Kukla says about subordination by slurs. I am not quite sure what her view is, but all of the possible readings prove unsatisfactory.

In the main part of this paper, I will discuss and modify Kukla's account of the speech act of interpellating in general (3.1). Following that, I will turn to slurs, i.e. in-

25 Kukla discusses second- and third-person uses of slurs separately, which I think is a useful approach. Because of the restrictions on the length of this article, I will only consider second-person uses. By a slur or an act of hate speech I mean in this paper a speech act in which members of an oppressed minority are addressed or talked about using a generic derogative term.

26 The case of interpellations with proper names calls for comment, because it is not obvious what category is in play here. What is the addressee called upon to recognize her- or himself as? I am not quite sure what Kukla would say, but it seems to me that there are certain assumptions about the personality of the bearer which are connected to the name, the public personality, as it were, how the name's bearer is known to others. The addressee is then called upon to be the person her or his friends, colleagues, etc. know her/him to be. 
terpellations with a specific kind of content, and explain in what sense they can be said to subordinate (3.2).

\subsection{Interpellations in General}

Before I turn to interpellations as a specific type of speech act, it will prove helpful to briefly consider the general theory of speech acts that Kukla has developed with Mark Lance. ${ }^{27}$ Here is a concise statement of its core principle:

Throughout this book we have taken it as a core principle that what a speech act [...] does is to draw upon the normative entitlements of its speaker in striving to change the normative commitments and entitlements of others. ${ }^{28}$

To illustrate Lance's and Kukla's theory, take the speech act of asserting. Claiming that $p$ changes (1.) what the speaker is committed to (she is now committed to $p$ and to whatever follows from $p$ ) and (2.) what the addressee is entitled to (he is entitled to the claim that $p$ because he can justify his reassertion that $p$ by saying that the speaker told him). Similarly, the speech act of ordering someone to do something creates a commitment for the addressee to perform a certain act; the speaker, in turn, draws on her entitlement to give orders to the addressee. Yet another case would be the speech act of promising, which creates a commitment for the speaker herself to perform a certain action. ${ }^{29}$

So, speech acts ${ }^{30}$ are acts of modification of the normative statuses of others. ${ }^{31}$ Bringing about such a change requires that the speaker is properly entitled or authorized. A clear example of this is Langton's legislator who changes the rights and duties of her or his subordinates by performing a law-enacting speech act, and who has to have the proper authority to bring about this effect. Lance and Kukla argue that if we take

27 Lance - Kukla, 2009. While Kukla does not explicitly invoke that theory but she defends it against an objection made by Swanson. It also emerges from her response to Swanson that what she calls interpellations in her 2018 article is pretty much what they call vocatives in the 2009 book.

28 Lance - Kukla 2009, 155. Lance and Kukla provide a more detailed summary in the section "Two Distinctions among Normative Statuses" (Lance - Kukla 2009, 12-18).

29 Lance - Kukla 2009, 12-18.

30 One is tempted to use Austin's concept of an illocutionary act, but Kukla says that she is avoiding this concept because Austin's illocutionary/perlocutionary distinction breaks down on her and Lance's theory (Kukla 2014, 453). Unfortunately, I cannot discuss this here.

31 According to Lance and Kukla 2009, 155, speech acts strive to "change the normative commitments and entitlements of others" (emphasis added). But it should be clear that they also affect the commitments of the speaker herself, most obviously in the case of promises. 
implicit normative statuses into account, we can observe structurally similar phenomena in the case of more ordinary speech acts as well.

Given this general structure of speech acts, the analysis of interpellations has to specify their input conditions and their normative output. What are the conditions that entitle or authorize a speaker to bring about an interpellation and what are the commitments and entitlements a properly authorized speaker thereby creates? I will start by reviewing and discussing what Kukla has to say about the normative output (3.1.1) and then turn to her discussion of their input conditions (3.1.2).

\subsubsection{The Normative Output of Interpellations}

With regard to the normative output of interpellations, it is important to stress (a) that a significant part of it concerns the addressee, rather than the speaker. I will then (b) discuss the way interpellations interact with the ideology. This will lead to (c) a modified way specifying the normative output of interpellations and (d) a content-related felicity-condition of interpellations.

(a) Kukla describes the normative output of interpellations as follows:

These hails are vocatives; they call out to a subject, second-personally, and call upon her to recognize herself as (already) the self she is being recognized as being, with the social identity and position she is recognized as having. ${ }^{32}$

The normative output is to "call upon" the addressee to "recognize herself", i.e. to think of herself in a certain way. Here, "calling on somebody to do something" can profitably be understood in terms of creating a commitment. ${ }^{33}$ When you call on somebody to do something (e.g. join the fight), you create a commitment for her to actually do so. Of course, the addressee can counter or avoid the commitment, by giving a reason not to follow or by simply excusing herself. She can also point out that the speaker has no authority to make a call of that kind upon her. ${ }^{34}$ In this sense, the commitment created is only prima facie. Put in another way, the normative output of an interpellation is to create normative pressure on the addressee to think of herself in certain terms (which, in turn, should translate into corresponding behavior).

32 Kukla 2018, 13.

33 Lance and Kukla 2009, 138-139 speak of a "duty" (in scare-quotes) that a hail creates for the addressee to react in a certain way.

34 Below, I will argue that every speaker has the authority to make interpellative calls on others, i.e. calls to recognize themselves in a certain way. For calls to other kinds of action, this may be different; it may be that calling upon someone to join the fight goes beyond the speaker's authority. 
It should be stressed that this normative output mainly concerns the addressee, rather than the speaker. Of course, when a speaker hails an addressee, she also creates commitments for herself: she gives expression to her recognition of the other as, say, a student, and thus commits herself to certain ways of thinking and acting. What is central for Kukla's account of slurs, however, is the normative output concerning the addressee. ${ }^{35}$

(b) So, with an interpellation, the speaker himself recognizes the addressee as having a certain identity and calls upon the addressee to recognize herself in that way. As a next step, I want to discuss how this is connected to the ideology. I follow Kukla in understanding the ideology as "a cluster of mutually supporting beliefs, interests, norms, values, practices, institutions, scripts, habits, affective dispositions, and ways of interpreting and interacting with the world". ${ }^{36}$ In many cases, these states are "implicit rather than conscious or intentionally endorsed". ${ }^{37}$ It will be important, moreover, that "[i]deologies and subjects with particular social identities are co-constituting". ${ }^{38}$ The ideology provides identities or social roles, such as being a doctor, student, father, but also gender roles, as well as racialized roles, and assigns them to individuals. ${ }^{39}$ Thus, it is part of the ideology that people with certain bodily characteristics play certain racialized roles, etc. For the purposes of this paper, it will furthermore be important that agents have several different roles and that they actively play only some of them at any given moment.

According to Kukla, interpellations stand in two relations to the ideology: they strengthen it and they cue it. ${ }^{40}$ For my account of the subordination by slurs, the cueing relation will be much more important than the strengthening relation. Since, moreover, the idea that speech acts strengthen the ideology by keeping it alive in people's heads is well known, I will not discuss this matter here. The idea that speech acts "cue the ideology" is less well known. This phrase has recently been coined by Eric Swanson. ${ }^{41}$ According to his first informal explanation, cueing the ideology means to put it into position and to give it a signal to do its work. Swanson provides an example (taken from a movie) which is set in an American college. There is an athletic event that a team

35 It is not always recognized that there is this addressee-regarding normative output. Swartzer 2019, 3, e.g. represents Kukla's account as follows: "In their central uses, then, slurs and similar forms of problematic discourse express a commitment to derogatory, subordinating ideologies." It is central for Kukla that the speaker not merely expresses a view or mental state she has, but also creates a commitment for the addressee to recognize herself.

36 Kukla 2018, 9; cf. Swanson forthcoming, 6.

37 Kukla 2018, 9.

38 Kukla 2018, 10.

39 Popa-Wyatt - Wyatt 2018, 2888 appropriate the terminology of social roles from Goffman. I take it that Kukla's identities are just roles in their sense.

40 Kukla 2018, 10; 21.

41 Swanson forthcoming, 9-10. 
of "jocks" from the school loses against a team of "nerds". In order to motivate the "jocks" to do better next time, the coach of the "jock"-team gives a speech in which he refers to the members of the opposing team as "nerds". This is a slur that is connected to an ideology, and by using it, the coach invokes this ideology to motivate his team. In this sense, the slur can be said to cue the ideology, i.e., to put it into position and to give it a signal to do its work. ${ }^{42}$

With reference to Swanson's article, Kukla proposes that “[u]nderstanding slurs as $[\ldots]$ interpellations helps make more precise the sense of the idea that slurs help to cue ideology". ${ }^{43}$ Interpellations "cue ideology by calling upon the one recognized to recognize herself as placed within ideology and to respond appropriately" ${ }^{44}$ So, interpellations do not simply call upon the addressee to subsume herself under a certain category, but rather to recognize that she is subsumed, according to the ideology, under that category.

In order to interpellate someone, one has to use a role term that is generally accepted as applying to the addressee - otherwise the interpellation misfires. Of course, there are also speech acts (verdictives, according to Austin's classification) of calling the addressee something that is not already part of the ideology, e.g. by saying "you're a genius" or "you are a diligent worker". Here, too, the speaker recognizes the addressee and calls upon her to recognize herself in a certain way, but still this is not an interpellation. One difference is that the addressee could react by saying "No, I am not".

(c) In light of these considerations, I propose to specify the normative output of interpellations in the following way: the addressee is called upon to actively play a role she already has according to the ideology, but which may be in the background when the speech act is performed. It is important here that subjects generally have several identities or social roles which guide their thinking and acting in different contexts. Against this background, it is possible for an interpellation to make a difference: a moment ago, the addressee may not have acted as a doctor, a police officer, or a student, but then, an interpellation calls upon her and creates a prima facie commitment for her to activate that role. By performing an interpellative speech act, the speaker cannot assign a new role or identity to the addressee, but he can call upon her to activate one she already has.

(d) If the normative effect of an interpellation is specified as the commitment of the addressee to actively play a certain role she already has, we can see that there is the fol-

42 Swanson, forthcoming, 9.

43 I left out "generic, derogatory, subordinating", because I think what helps us understand how slurs do this is that they are interpellations, not that their content is "generic, derogatory, subordinating". And, in the end of this passage, she says: "Thus, like interpellation more generally, slurs at once constitute subjects in ideology and draw on ideology to recognize and place subjects." - So cueing the ideology is something interpellations in general do.

44 Kukla 2018, 21 (emphasis added). 
lowing felicity condition concerning the content of an interpellation. For the interpellation to be brought off, i.e., for the normative output to be produced, the following requirement with regard to the content expressed has to be met: ${ }^{45} \mathrm{I}$ can only hail someone using a role term or proper name that is generally taken to apply to that someone. If I use a wrong name or the wrong profession or social role, the interpellation misfires. Obviously, the call to actively play a role presupposes that one in fact has this role.

For example, if a speaker is mistaken and tries to interpellate someone as a doctor who in fact is not a doctor, the interpellation fails. His utterance does not create a commitment for the addressee to act according to a certain part of her identity, that of being a doctor. The proper reaction for third party speakers would not be to expect the addressee to act in a certain way, but rather to say that the speaker is mistaken. ${ }^{46}$

\subsubsection{The Authority to Interpellate}

One of the conditions of adequacy of an account of hate speech is that speech acts of this kind should not require any special authority to be brought off. In this regard, the following quote from Kukla's article seems troubling: "[interpellations] have to be undergirded by the proper authority in order to work" because "in some sense, all interpellations are exercises of power". ${ }^{47}$

In their book, Lance and Kukla provide convincing examples illustrating that interpellations are exercises of power:

[V]ocatives [i.e., interpellations] can so easily be received as abusive, burdensome, or obtrusive: consider, for instance, how a man's hailing of a woman he doesn't know in a bar, or a homeless person's attempt to hail me as I pass on the street, can be received as an uncomfortable or onerous demand for a response. ${ }^{48}$

In my view, Lance and Kukla are right to point out that interpellations make demands that can be experienced as burdensome. This seems to lend support to the view that not any speaker can make these demands and that one has to occupy an authori-

45 There are many speech act types with content-related felicity-conditions. Promising is maybe the clearest example: the act specified in the content of the promise has to be one that lies in the future, is at least in principle within the power of the speaker, and is desired by or in the interest of the addressee.

46 If one cannot plausibly assume a mistake because the speaker knows that the addressee is not a doctor very well, another possible reaction would be to re-interpret the utterance as a verdictive speech act that ascribes medical skills.

47 Kukla 2018, 20; cf. 13.

48 Lance - Kukla 2009, 141. 
tative position with regard to the addressee in order to be able to interpellate her or him. On the other hand, Maitra's subway-rider example and the examples in the above quote show that nothing extraordinary seems to be required in this regard. A total stranger can hail you.

In her article, Kukla does not explain what kind of authority is required or who has it and who does not. My view is this: Bringing off an interpellation indeed requires a certain authority, but this authority is not a special authority that only some speakers have and that is tied to a special social position. The relevant kind of authority is one that every speaker of the language has over her fellow speakers. Everybody has the power to summon anybody else's attention by a hail.

This is also the view Lance and Kukla endorse in their book. In our rather egalitarian modern society, everybody is authorized to interpellate anybody else. However, one can imagine more hierarchical societies in which ordinary people lack the authority to interpellate the king. ${ }^{49}$ Lance and Kukla add, however, that for interpellations with a certain kind of content, a special authority may be required:

Different people have the right to call one another in different ways and in different situations, and to call one another different things. A doctor's patients may only be able to appropriately call her by her title and last name, whereas her friends can call her by her first name, and her parents can call her by an endearing albeit undignified nickname. ${ }^{50}$

In my view, the case of the doctor and her patient does not necessarily show that the speaker lacks the authority to bring off the interpellation. In fact, I think this case is better understood by saying that the patient has successfully interpellated the doctor, but that doing so violates the norms of etiquette. By using the doctor's first name, the speaker (who is her patient) does indeed call upon her to assume her identity as a friend, but given the patient-doctor relation, it is inappropriate for her to do so.

Be that as it may, what is relevant for the purposes of this paper is that slurs are not among the interpellations that only friends and family or members of some other group can use. Bringing off a slur only requires the general authority that is part of the status of being a speaker of the language.

\subsection{Slurs as Interpellations with Derogatory Content}

Kukla proposes to understand slurs as "interpellations of a specific sort":

49 Lance - Kukla 2009, 140.

50 Lance - Kukla 2009, 140. 
They are hails that, like all interpellations, recognize a subject [...] as having a specific identity [...]. Specifically, they are interpellations that recognize a subject $[\ldots]$ as having a (1) generic, (2) derogated, and (3) subordinated identity. ${ }^{51}$

As I have noted above, the speech act of interpellating has a certain content - the role or identity the speaker recognizes the addressee as having and calls upon her to recognize herself as having. In the case of slurs, this is a generic, derogated and subordinated identity. The identity in question is generic, because it is one addressees have in virtue of belonging to a social group. Obviously, many interpellations have generic content. What is specific about slurs, however, is that this identity is derogated and subordinated. This is the case insofar as the identity in question is one of being a person of lesser value, a person whom it is appropriate to exclude, mistrust, etc.

Adopting this proposal of what slurs are, I will first discuss Kukla's account of the sense in which they constitute subordination (3.2.1) before I turn to my own, alternative proposal (3.2.2).

\subsubsection{Kukla on Subordination by Slurs}

Above I have discussed Kukla's claim that interpellations in general (and not just slurs) are exercises of power, insofar as they create a potentially burdensome commitment for the addressee. Therefore, all interpellations can in some sense be said to subordinate. However, there still is a difference between interpellating someone as, e.g. a doctor and by using a slur-word. The latter speech act subordinates in a sense in which the former does not. Even if it is still unclear how subordination in this stronger sense is to be understood, it seems clear that it must have something to do with the semantic content of slurs, because that is what distinguishes them from other, non-subordinating interpellations.

It is not quite clear to me how Kukla wants to understand subordination in this stronger sense. She writes that "slurs exercise power by positioning the interpellator above the one interpellated on some sort of hierarchy, at least locally". ${ }^{52}$ It remains unclear in what sense "position" is to be understood here. I will discuss different readings, all of which prove unsatisfactory, and then proceed to present my own account of how slurs subordinate.

The first possibility is to read "position" in the sense of "depicting". According to this reading, Kukla would be saying that slurs depict social reality in such a way that a 
certain group occupies a low social position. While I would agree that some such assumption is implicit in the content of slurs, this reading would understand subordination by slurs merely along its "locutionary dimension" ${ }^{53}$ Clearly, what a slur does goes beyond describing or depicting social reality in a certain way.

According to a stronger reading of "position", slurs position the addressee in the sense of making it the case that she is in a subordinated social position. This is, in turn, could be intended in at least the following two ways: first, this might be understood in analogy to the law-enacting speech acts of Langton's legislator who can put a group of people in a lower social position. ${ }^{54}$ This, however, is hardly what Kukla has in mind, given the way she describes the normative output of interpellations.

Second, Kukla's point might be that slurs make it the case that others are in a subordinated position because they strengthen the ideology, which in turn makes it the case that they are in a subordinated position. For different reasons, this is unsatisfactory as an account of subordination by slurs. The first reason is that an individual speech act's contribution to the ideology is tiny. The subordinating effect of a slur seems to be much more serious than the minuscule gain in strength of an already strong ideology.

The second reason why subordination by slurs cannot be understood exclusively in terms of their strengthening effect on the ideology is this: the subordinating effect of a slur is directed specifically at the addressee of the speech act and not at the members of the subordinated group in general. (In the above quote, Kukla speaks of the subordination of "the one interpellated", i.e., an individual person, not a group.) Subordination via the strengthening of the ideology, on the other hand, affects all members of the group in question.

A third reason to be dissatisfied with the answer that slurs subordinate by strengthening the ideology is that we are looking for an account of the sense in which acts of hate speech constitute, rather than cause subordination, i.e., a sense in which the speech act in itself subordinates. According to the reading discussed, however, it seems that what the speech act in itself does is to strengthen the ideology which then, in turn, subordinates. So, if subordination by slurs is understood in this way, subordination seems to be caused, rather than constituted.

\subsubsection{An Alternative Account of Subordination by Slurs}

In order to understand the way in which slurs subordinate, one first has to take into account the way in which interpellations in general interact with the ideology. As I have

53 Langton 1993, 307.

54 Langton 1993, 302. 
argued above, the normative output of interpellations is best described as a prima facie commitment of the addressee to think and act according to a social role she has, but which she might not be actively playing at the moment. In the case of a slur, the addressee is called upon to think and act according to an identity which involves thinking of herself as being a person of lesser value, who deserves to be mistrusted, suspected, slighted, excluded, etc.

In virtue of this, a slur can be said to subordinate in a way in which hailing someone as a doctor or a student does not. In these latter cases, too, the addressees are called upon to "activate" certain roles they already have, but doing so does not involve them thinking of themselves in a negative way.

To illustrate the difference a slur can make, let us assume that $A$ is a member of the non-subordinated majority who is interacting with her colleague $B$, a member of an ideologically subordinated group. A can interpellate B using a work-related role term. This does not subordinate B, because A merely calls upon her to pay attention to a certain work-related identity she has and to give it more weight in her practical behavior. However, A can also use a slur to interpellate B; in this case, too, A calls upon B to pay attention to an identity she has, but this time as a person of lesser value. In virtue of this, the slur constitutes subordination of the addressee in a sense in which other interpellations do not.

\section{Conclusion}

In this article, I have proposed a way to understand the claim that hate speech not only causes, but also constitutes subordination. I have adopted an approach that has generated a lot of interest in recent years, according to which acts of hate speech subordinate in virtue of the normative effects or output they generate.

My proposal as to how acts of hate speech constitute subordination builds on and refines Kukla's. Following Kukla, I assume that central cases of hate speech are, regarding the type of speech act, interpellations or vocatives, and that slurs are interpellations with a certain kind of content. I adopt Lance and Kukla's general theory of speech acts, according to which they strive to change the commitments and entitlements of others.

Building on Kukla's account, I have argued that this normative output is best understood as a call on the addressee to activate an identity or a social role she has anyway, but which may be in the background when the act of hate speech is performed. I have argued that no special authority is required to make such a call. The speaker, as it were, 
merely changes the social context such that a different role of the addressee is activated. Since the collectively accepted ideology determines what this role requires and that the addressee occupies it, interpellations can be said to cue the ideology.

Finally, I have proposed an explanation of the sense in which slurs constitute subordination. They do so because they call upon the addressee to actively play a derogated, subordinated role. Again, it is part of the ideology that the addressee occupies this role, but the role may have been in the background when the slur was performed.

\section{Bibliography}

Austin, John L. 1962. How to Do Things with Words. London: Oxford University Press.

Goldman, Alvin I. 1970, A Theory of Human Action. Englewood Cliffs, NJ: Prentice-Hall.

Kukla, Rebecca. 2014. "Performative Force, Convention, and Discursive Injustice." Hypatia 29/2: 440-457. DOI: 10.1111/j.1527-2001.2012.01316.x.

Kukla, Rebecca. 2018. "Slurs, Interpellation, and Ideology." Southern Journal of Philosophy 56/ S1: 7-32. DOI: 10.1111/sjp.12298.

Lance, Mark - Rebecca Kukla. 2009. 'Yo!' and 'Lo!': The Pragmatic Topography of the Space of Reasons. Cambridge, Mass.: Harvard University Press.

Langton, Rae. 1993. "Speech Acts and Unspeakable Acts." Philosophy and Public Affairs 22/4: 293-330. DOI: 10.1093/acprof:oso/9780199247066.003.0002.

Maitra, Ishani. 2012. "Subordinating Speech." In Speech and Harm: Controversies Over Free Speech, edited by Mary Kate McGowan - Ishani Maitra, 94-120. Oxford: Oxford University Press.

Maitra, Ishani - Mary Kate McGowan. 2012. Speech and Harm: Controversies Over Free Speech. Oxford: Oxford University Press.

McGowan, Mary Kate. 2004. "Conversational Exercitives: Something Else We Do with Our Words.” Linguistics and Philosophy 27: 93-111. DOI: 10.1023/B:LING.0000010803.47264. f0.

McGowan, Mary Kate. 2009. "Oppressive Speech.” Australasian Journal of Philosophy 87/3: 389-407. DOI: 10.1080/00048400802370334.

Popa-Wyatt, Mihaela - Jeremy L. Wyatt. 2017. "Slurs, Roles and Power." Philosophical Studies 175: 2879-2906. DOI: 10.1007/s11098-017-0986-2.

Swanson, Eric. forthcoming. "Slurs and Ideologies." [http://www-personal.umich.edu/ - ericsw/ research/Swanson, $\% 20$ Slurs\%20and\%20Ideologies $\% 20$ November\%202015.pdf] (2021.02.11.)

Swartzer, Steven. 2019. "Race, Ideology, and the Communicative Theory of Punishment." Philosophers' Imprint 19/53: 1-22. 